\title{
ASSESSING THE ACCURACY OF GLOBE THERMOMETER METHOD IN PREDICTING OUTDOOR MEAN RADIANT TEMPERATURE UNDER MALAYSIA TROPICAL MICROCLIMATE
}

\author{
N.G. Khrit ${ }^{\text {a }}$, M.A. Alghoul ${ }^{*},{ }^{\text {b,c }}$, K. Sopian*, a , A.A. Lahimer ${ }^{\text {a }}$, and O.K. \\ Elayeb $^{\mathbf{a}}$ \\ ${ }^{a}$ Solar Energy Research Institute, Universiti Kebangsaan Malaysia, 43600 Bangi, Selangor, \\ Malaysia \\ ${ }^{b}$ Energy and Building Research Center, Kuwait Institute for Scientific Research, P.O. Box \\ 24885, Safat 13109, Kuwait \\ ${ }^{c}$ Center of Research Excellence in Renewable Energy (CoRe-RE), Research Institute, King Fahd \\ University of Petroleum and Minerals (KFUPM), Dhahran 31261, Saudi Arabia \\ *Corresponding authors: dr.alghoul@gmail.com (M.A.Alghoul),ksopian@ukm.edu.my (K. \\ Sopian)
}

\begin{abstract}
:
Assessing outdoor human thermal comfort and urban climate quality require experimental investigation of microclimatic conditions and their variations in open urban spaces. For this, it is essential to provide quantitative information on air temperature, humidity, wind velocity and mean radiant temperature. These parameters can be quantified directly except mean radiant temperature $\left(\mathrm{T}_{\mathrm{mrt}}\right)$. The most accurate method to quantify $\mathrm{T}_{\mathrm{mrt}}$ is integral radiation measurements (3-D shortwave and long-wave) which require using expensive radiometer instruments. To overcome this limitation the well-known globe thermometer method was suggested to calculate $T_{\text {mrt. }}$ The aim of this study was to assess the possibility of using indoor globe thermometer method in predicting outdoor mean radiant temperature under Malaysia tropical microclimate. Globe thermometer method using small and large sizes of black-painted copper globes $(50 \mathrm{~mm}, 150 \mathrm{~mm})$ were used to estimate $T_{\text {mrt }}$ and compare it with the reference $T_{\text {mrt }}$ estimated by integral radiation method. The results revealed that the globe thermometer method considerably overestimated $T_{\text {mrt }}$ during the middle of the day and slightly underestimated it in the morning and late evening. The difference between the two methods was obvious when the amount of incoming solar radiation was high. The results also showed that the effect of globe size on the estimated $\mathrm{T}_{\mathrm{mrt}}$ is mostly small. Though, the estimated $\mathrm{T}_{\text {mrt }}$ by the small globe showed a relatively large amount of scattering caused by rapid changes in radiation and wind speed.
\end{abstract}

\section{INTRODUCTION}

Mean radiant temperature $\left(\mathrm{T}_{\mathrm{mrt}}\right)$ is one of the key variables in the calculation of human energy balance and the assessment of thermal comfort through thermal indices. The concept of $T_{\text {mrt }}$ considers radiative heat exchange between a human body and its surrounding which causes an energy gain -or loss- of a person depending on their surface temperatures and emissivity. It is defined as the uniform temperature of a hypothetical spherical surface surrounding the subject (emissivity 
$\varepsilon=1)$ that would result in the same net radiation energy exchange with the subject as the actual, complex radiative environment [1].

The determination of $\mathrm{T}_{\text {mrt }}$ is important for the assessment of human bioclimatology and heat stress in the urban environments. In such environments the radiation fluxes densities are highly influenced by urban structures that absorb, emit, reflect radiative energy in the shortwave and longwave spectrum [2]. This results in spatial and temporal variation in radiation fluxes densities, as well as radiant non-uniformity [2, 3]. Quantitative information of short- and long wave radiation fluxes is essential for an accurate estimation of the $\mathrm{T}_{\mathrm{mrt}}$ [4]. For this detailed integral radiation measurements of radiation fluxes have been developed and used as a way to determine $\mathrm{T}_{\mathrm{mrt}}$ [2-5]. The method offers significant advantages in terms of accuracy and fast response; however, it requires complex and costly equipment. Any attempt to use the method for further understanding of $\mathrm{T}_{\text {mrt }}$ from temporal and spatial scales (i.e., multi-site field measurements) is impractical and costly [6].

A simple and inexpensive method for estimating $\mathrm{T}_{\mathrm{mrt}}$ is globe thermometer method [7]. It was developed and is commonly used for indoor environments [7, 8]. However, in outdoor environments with high intensity and variability of climate data, the accuracy of globe thermometer is sometimes unacceptable [5, 6, 9]. Despite of that, it is still attracting the attention as an alternative and low cost method for further evaluation in outdoor environment $[2,3,5,10,11]$.

So far, limited researches in the literature compared globe thermometer method with the integral radiation measurements (radiometers) for the estimation of $\mathrm{T}_{\text {mrt }}$ under sub-tropical [12,13] and tropical climate zones [5]. Kántor et al. (2014) compared measurements of standard $150 \mathrm{~mm}$-black globe thermometer with integral radiation measurements in order to improve the assessment of outdoor thermal comfort in subtropical Taiwan [13]. Tan et al. (2013) used a smaller (38 $\mathrm{mm}$ in diameter) graypainted acrylic globe to validate the globe method by six-directional measurements in Singapore and suggested a modified $T_{\text {mrt }}$ equation to obtain better values of $T_{m r t}$ [5]. Therefore, the aim of this study is to examine the accuracy of two black-painted hollow copper globes $(50 \mathrm{~mm}$ and $150 \mathrm{~mm})$ in estimating $T_{m r t}$ in the tropical outdoor urban setting of Malaysia when compared with the integral radiation measurements as a reference method. Also the effect of the globe diameter on the estimated $\mathrm{T}_{\mathrm{mrt}}$ is investigated to determine whether the two globe thermometers are equally suitable for estimating $\mathrm{T}_{\mathrm{mrt}}$ in tropical urban setting, or if each size has different estimation accuracy of the $\mathrm{T}_{\mathrm{mrt}}$. 


\section{MATERIALS AND METHOD}

\subsection{Measurement site and microclimate station unit}

The measurement site is located at a pedestrian walkway at the main campus of the National University of Malaysia, Bangi, Malaysia $\left(2^{\circ} .55^{\prime} \mathrm{N}, 101^{\circ} .46^{\prime} \mathrm{E}\right)$. The main campus is spatially constrained by abutting landscape and tropical rainforest that necessitated the densification of the built environment at the university. The floor of the pedestrian walkway is made of flat concrete bricks and the adjacent buildings facades are made of red brick and grey concrete. The measurement site and the microclimate station unit are shown in Fig 1(a) and Fig 1(b), respectively.

(a)
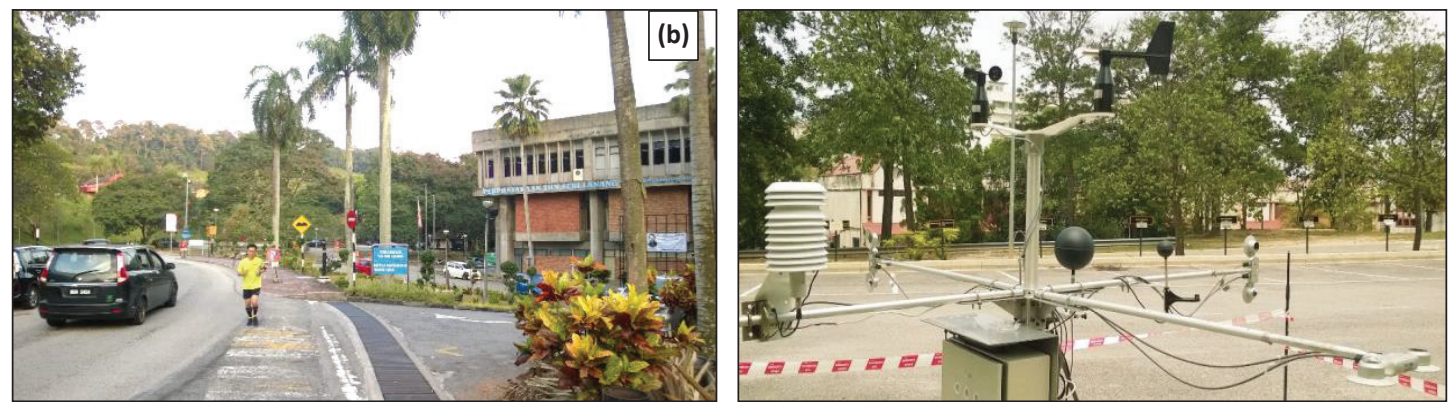

Fig. 1(a-b): (a) The measurement site at the pedestrian walkway, (b) Microclimate station unit for measuring three-dimensional short and long-wave radiation fluxes, besides two globe thermometers of $50 \mathrm{~mm}$ and $150 \mathrm{~mm}$ diameters.

As shown in Fig 1(b), a microclimate station was equipped with a set of instruments as defined in Table 1. This includes sensors to measure air temperature, relative humidity, and wind speed. Three net radiometers, each consists of two pyranometers and two pyrgeometers, were set up on the station stand and oriented in east-west, north-south, upward and downward directions in order to measure the threedimensional short and long-wave radiation fluxes. Two black-painted copper globe thermometers of $50 \mathrm{~mm}$ and $150 \mathrm{~mm}$ in diameters were installed within the space enclosed by the radiometers. The instruments were fixed at the same measuring point as much as possible and at a height of approximately $1.1 \mathrm{~m}$ above the ground. The three-cup anemometer was set at height of $1.5 \mathrm{~m}$ above the ground. The recording interval was set to 2-min-averages of $10 \mathrm{~s}$ scan for radiation fluxes, and 2-minaverages of 30s scan for other microclimatic data. 
Table 1: Measured parameters and instruments

\begin{tabular}{l|l}
\hline \multicolumn{1}{c|}{ Quantity } & \multicolumn{1}{c}{ Instrument } \\
\hline $\begin{array}{l}\text { Air temperature, } \mathrm{T}_{\mathrm{a}} \\
\text { 50-mm globe temperature, } \mathrm{T}_{\mathrm{g} 1}\end{array}$ & $\begin{array}{l}\text { Skye rht+ PT100 sensor } \\
\text { Delta ohm, TP3276.2, PT100 sensor. } \\
\text { 150-mm globe temperature, } \\
\mathrm{T}_{\mathrm{g} 2}\end{array}$ \\
$\begin{array}{l}\text { Air speed, } \mathrm{V}_{\mathrm{a}} \\
\text { Delta ohm, TP3275, PT100 sensor. }\end{array}$ \\
$\begin{array}{l}\text { Relative humidity, RH } \\
\text { Shortwave and longwave } \\
\text { radiation, K, L }\end{array}$ & $\begin{array}{l}\text { Delta ohm, Probe with } \\
\text { omnidirectional hot wire } \\
\text { Skye rht }+\end{array}$ \\
\hline
\end{tabular}

\section{MEAN RADIANT TEMPERATURE ESTIMATION METHODS}

\subsection{Integral (3-dimensional) radiation measurement method}

This method provides the most accurate estimate of the $T_{\text {mrt }}[6,9]$. A mean radiant flux density $\left(\mathrm{S}_{\mathrm{str}}\right)$ have to be calculated first to determine a part of the radiation that is significant to a person [1]. $\mathrm{S}_{\mathrm{str}}$ is a summation of the measurements of radiation fluxes from all six directions multiplied by the angular factors between a person and the surrounding surfaces, according to this equation $[1,9]$.

$$
S_{s t r}=\alpha_{k} \sum_{i=1}^{6} K_{i} F_{i}+\varepsilon_{p} \sum_{i=1}^{6} L_{i} F_{i}
$$

$K_{i}=$ the short-wave radiation fluxes $(i=1-6)$

$L_{i}=$ the long-wave radiation fluxes $(i=1-6)$

$\alpha_{k}=$ the absorption coefficient for short-wave radiation (standard value 0.7)

$\varepsilon_{p}=$ the emissivity of the human body (standard value 0.97 )

$F_{i}=$ the angular factors between a person and the surrounding surfaces $(i=1-6)$.

For a standing -or walking- person, $F_{\mathrm{i}}$ is commonly set to 0.22 for radiation fluxes from the horizons and 0.06 for upward and downward radiation fluxes. For a sphere, $F_{i}$ is 0.167 for all six directions. 
The mean radiant temperature can be calculated in ${ }^{\circ} \mathrm{C}$ using equation $(2)[1,9]$ :

$$
T_{m r t}=\left[\frac{S_{s t r}}{\varepsilon_{p} \sigma}\right]^{0.25}-273.15
$$

Where, $\sigma$ is the Stefan-Boltzmann constant $\left(5.67 \times 10^{-8} \mathrm{Wm}^{-2} \mathrm{~K}^{-4}\right)$

\subsection{Globe thermometer method}

The method requires measurements of globe temperature in combination with measurements of air temperature and wind speed. Its theory was explained thoroughly by Kuehn et al., (1970) [14]. In the theory, when a globe thermometer is in equilibrium, the heat gained (or lost) by radiation is equal to the heat lost (or gained) through convection. Globe temperature represents a weighted average between radiant and ambient temperatures $[5,6,9]$. The formula to calculate the $T_{m r t}$ is given by [7]:

$$
T_{\mathrm{mrt}}=\left[\left(T_{\mathrm{g}}+273.15\right)^{4}+\frac{1.06 \times 10^{8} V_{\mathrm{a}}^{0.6}}{\varepsilon D^{0.4}} \times\left(T_{\mathrm{g}}-T_{\mathrm{a}}\right)\right]^{0.25}
$$

Where $T_{\mathrm{g}}$ is the globe temperature $\left({ }^{\circ} \mathrm{C}\right), T_{\mathrm{a}}$ is the air temperature $\left({ }^{\circ} \mathrm{C}\right), V_{a}$ is the air speed $(\mathrm{m} / \mathrm{s}), \varepsilon$ is the globe emissivity ( 0.95 for a black globe) and $D$ is the globe diameter $(\mathrm{m})$. The weighting parameter $1.06 \times 10^{8} V_{\mathrm{a}}^{0.6}$ represents the globe's mean convection coefficient.

\section{RESULT AND DISCUSSION}

This case study was carried out in a greenery open urban space; the obtained results were based on one-day measurement in warm-humid conditions and intense solar radiation. The measurements were conducted on $8^{\text {th }}$ October 2016 from 09:30 to 21:00 local time. The weather in this day brought hot humid conditions with a maximum air temperature of $33.9^{\circ} \mathrm{C}$, average air temperature of $30.7^{\circ} \mathrm{C}$ and average wind speed of $1.29 \mathrm{~m} / \mathrm{s}$.

\subsection{Three-dimensional short and long-wave radiation fluxes}

The temporal course of shortwave fluxes from the four cardinal points $\mathrm{K}_{\text {east }}, \mathrm{K}_{\text {west }}$, $\mathrm{K}_{\text {north }}$ and $\mathrm{K}_{\text {south }}$, as well as downward/incoming and upward/outgoing shortwave 
fluxes $\mathrm{K} \downarrow$ and $\mathrm{K} \uparrow$ are shown in Fig. 2 (a). The high variation in shortwave radiation fluxes can be explained by rapid changes in weather conditions from clear to cloudy conditions. This resulted in a sharp fluctuation in $\mathrm{K} \downarrow$ with a maximum value of 1042 $\mathrm{W} / \mathrm{m}^{2}$ recorded at 11:42. The upward shortwave radiation $\mathrm{K} \uparrow$ followed the same pattern of $\mathrm{K} \downarrow$ but with much less amounts (dependent on angle of incidence and surface albedo). Its maximum value $\left(161.1 \mathrm{~W} / \mathrm{m}^{2}\right)$ was recorded at the same time that the maximum $\mathrm{K} \downarrow$ was recorded. In the morning when the site was sunny from east, $\mathrm{K}_{\text {east }}$ reached its maximum record of $450 \mathrm{~W} / \mathrm{m}^{2}$ at $09: 54$. When the site was sunny from west, $\mathrm{K}_{\text {west }}$ exhibited sharp increase $\left(462 \mathrm{~W} / \mathrm{m}^{2}\right)$ around 17:35.
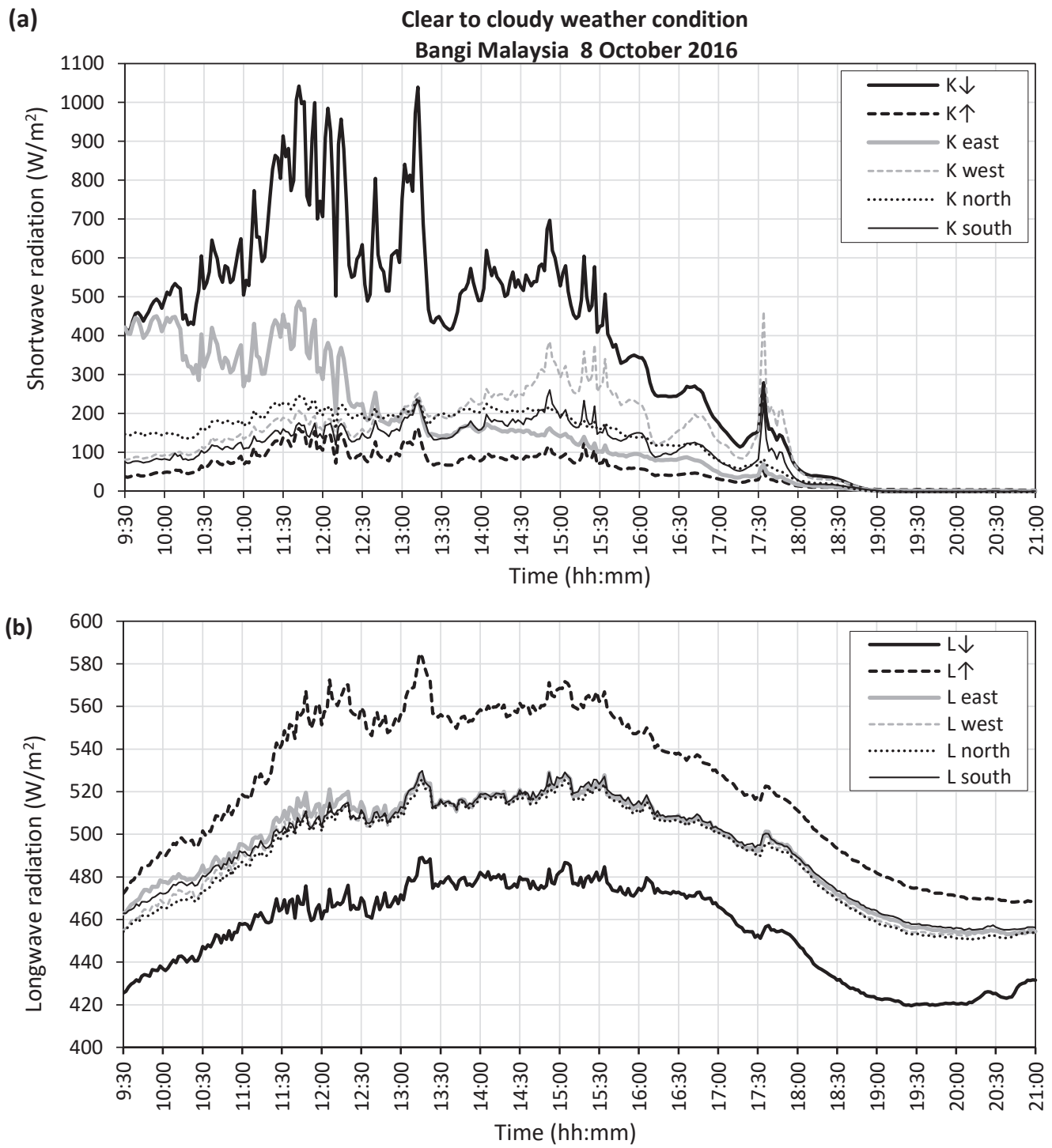

Fig. 2: (a-b): Three-dimensional shortwave and longwave radiation fluxes. 
As shown in Fig. 2 (b), longwave radiation fluxes from the four cardinals, $\mathrm{L}_{\text {east }}, \mathrm{L}_{\text {west }}$, $\mathrm{L}_{\text {north }}$ and $\mathrm{L}_{\text {south }}$ were close and ranged from 450 to $530 \mathrm{~W} / \mathrm{m}^{2}$, reaching their maximum in the afternoon. Longwave radiation from the sky $\mathrm{L} \downarrow$ was lowest during the day, with a maximum record of $489 \mathrm{~W} / \mathrm{m}^{2}$ at 13:14. The upward long-wave radiation $\mathrm{L} \uparrow$ was the highest amongst all longwave fluxes, with a maximum of 585 $\mathrm{W} / \mathrm{m}^{2}$ at $13: 14$. This was due to low albedo and high emissivity of the concrete floor, causing higher absorption of solar radiation and increased surface temperature and thus higher emittance of $\mathrm{L} \uparrow$.

\subsection{Validation of globe thermometer in a tropical outdoor setting}

In this study, two globe thermometers of different diameters $(50 \mathrm{~mm}$ and $150 \mathrm{~mm}$ ) were used; each consisted of a black-painted hollow copper sphere with temperature sensor in its centre. Temperatures registered for small globe $\mathrm{T}_{\mathrm{g} 1}$ and for large globe $\mathrm{T}_{\mathrm{g} 2}$, as well as air temperature $\mathrm{T}_{\mathrm{a}}$ and wind speed $\mathrm{V}_{\mathrm{a}}$ were used to estimate mean radiant temperatures $T_{\mathrm{mrt}(\mathrm{g} 1)}$ and $\mathrm{T}_{\mathrm{mrt}(\mathrm{g} 2)}$ according to equation (3). Integral radiation measurements from the net radiometers were used to obtain the reference mean radiant temperature, $T_{\text {mrt (rad.) }}$ for a standing person. As shown in Fig. 3, the rapid change in solar radiation caused a high variation in $\mathrm{T}_{\mathrm{mrt}}$ (rad.), and may also be reflected in the globe thermometers measurements. The maximum $\mathrm{T}_{\text {mrt (rad.) }}$ was 70.6 ${ }^{\circ} \mathrm{C}$ and occurred at which the maximum $\mathrm{K} \downarrow$ occurred, that is at 11:42.

The estimated $\mathrm{T}_{\mathrm{mrt}}(\mathrm{g} 1)$ and $\mathrm{T}_{\mathrm{mrt}}$ (g2) from globe thermometer measurements considerably overestimated $\mathrm{T}_{\text {mrt }}$ during the middle of the day; however they tended to underestimate it in the morning and late evening. The difference between the two methods was obviously high when the amount of incoming solar radiation was high. The highest difference between $\mathrm{T}_{\mathrm{mrt}}$ (rad.) and $\mathrm{T}_{\mathrm{mrt}}(\mathrm{g} 1)$ was $31.7^{\circ} \mathrm{C}$, which occurred at 11:36, while the highest difference between $\mathrm{T}_{\mathrm{mrt}(\mathrm{rad} .)}$ and $\mathrm{T}_{\mathrm{mrt}}(\mathrm{g} 2)$ was $26.9^{\circ} \mathrm{C}$, which occurred at the same time. The general form of this finding has been confirmed in earlier studies $[9,11,12,15-17]$. The high absorption of the black globe to shortwave radiation causes $T_{m r t}$ to be overestimated. The maximum $T_{m r t}(\mathrm{~g} 1)$ by the small globe was $95.2^{\circ} \mathrm{C}$, while the maximum $\mathrm{T}_{\mathrm{mrt}}$ (g2) by the large globe thermometer was $91.5^{\circ} \mathrm{C}$ at $11: 42$. The difference between $\mathrm{T}_{\mathrm{mrt}(\mathrm{g} 1)}$ and $\mathrm{T}_{\mathrm{mrt}(\mathrm{g} 2)}$ is mostly small during the day.

Also as shown in Fig. 3, the difference in globe size results in obviously different globe temperatures. The large globe temperature $\mathrm{T}_{\mathrm{g} 2}$ was higher than the small globe temperature $T_{\mathrm{g} 1}$ throughout daytime, except in the morning and late evening, with a highest difference of $4.7^{\circ} \mathrm{C}$, which occurred at 13:14. 


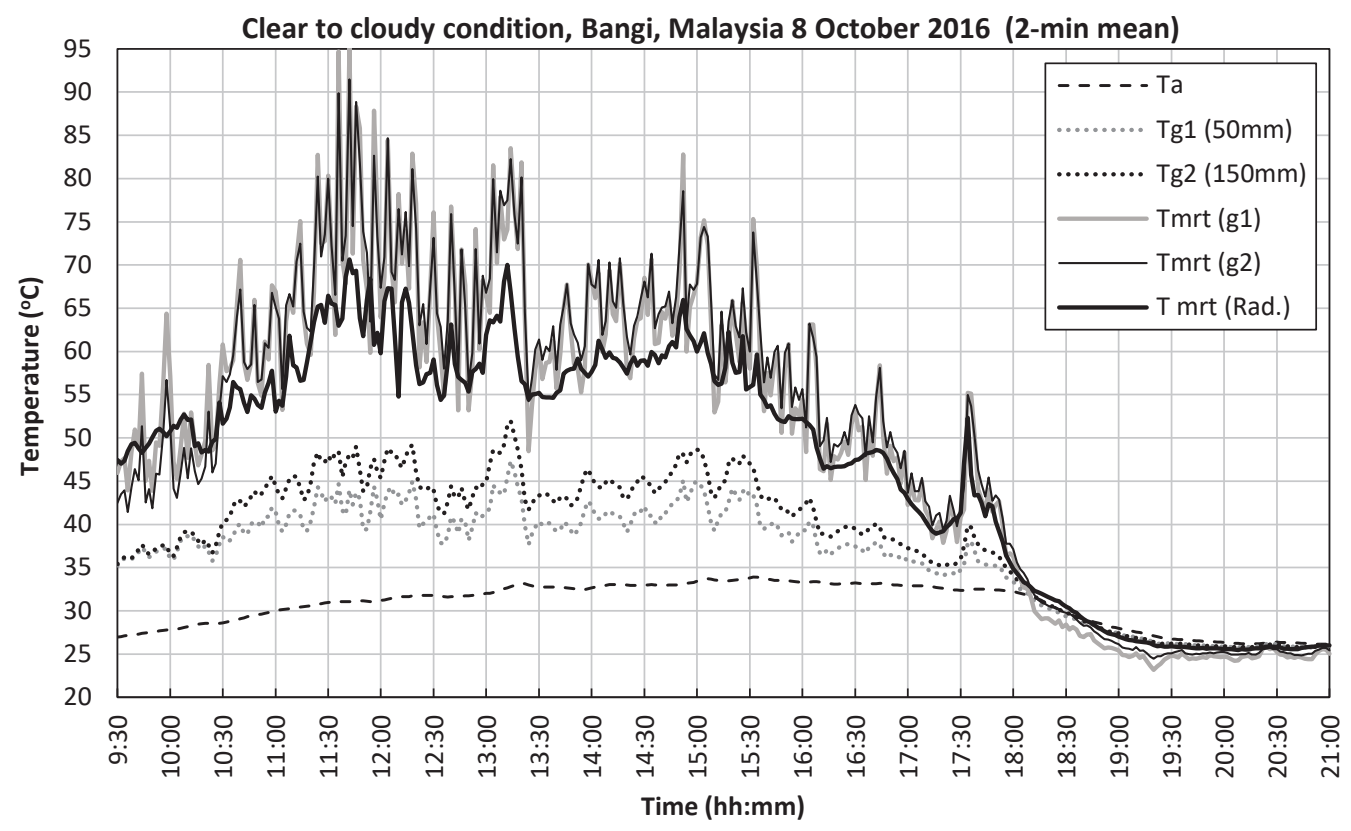

Fig. 3. Temperatures of the $50 \mathrm{~mm}$ globe $\left(\mathrm{T}_{\mathrm{g} 1}\right), 150 \mathrm{~mm}$ globe $\left(\mathrm{T}_{\mathrm{g} 2}\right)$ and air temperature $\left(\mathrm{T}_{\mathrm{a}}\right)$. Estimated $\mathrm{T}_{\text {mrt }}$ using integral radiation measurements, $\mathrm{T}_{\mathrm{mrt}}$ (rad.) and estimated $T_{m r t}$ using globe thermometer of $50 \mathrm{~mm}$ diameter, $T_{\mathrm{mrt}}(\mathrm{g} 1)$ and $150 \mathrm{~mm}$ diameter, $\mathrm{T}_{\mathrm{mrt}(\mathrm{g} 2)}$.

\subsection{Effect of the globe size and outdoor condition on the response time}

In Fig. 3, there was a large amount of scattering in $\mathrm{T}_{\mathrm{mrt}}$ data. This was because of the delay in the globes' response to rapid changes in radiation and wind speed. The response of the standard black globe is too long; it takes about 15 min to reach equilibrium $[12,16]$. Thus, in case of rapidly changing outdoor conditions, the globe equilibrium is never reached, resulting in scatter in $T_{\text {mrt }}$ data $[1,9]$.

It is also seen that the small globe thermometer has a faster response than the large one. As shown in Fig. 4 (a), this resulted in a rather larger scatter in the estimated $\mathrm{T}_{\text {mrt (g1) }}$ by the small globe (lower $\mathrm{R}^{2}$ ). This finding agreed with results of other researchers $[6,9,12,15-17]$, who reported that downsized globe thermometers (less than $50 \mathrm{~mm}$ in diameters) have faster response time $(5-10 \mathrm{~min})$ but also give a relatively larger scatter in $T_{\text {mrt }}$ values. The results in Fig. 4 (a) indicate that the accuracy of $\mathrm{T}_{\mathrm{mrt}}(\mathrm{g} 1)$ and $\mathrm{T}_{\mathrm{mrt}}(\mathrm{g} 2)$ was reduced considerably when the amount of shortwave radiation increased. This can be clarified in Fig. 4 (b) by plotting the difference between $\mathrm{T}_{\mathrm{mrt}(\mathrm{g} 1)}$ and $\mathrm{T}_{\mathrm{mrt}}$ (rad.) and between $\mathrm{T}_{\mathrm{mrt}(\mathrm{g} 2)}$ and $\mathrm{T}_{\mathrm{mrt} \text { (rad.) }}$ against $\mathrm{K} \downarrow$. As shown, the black colour of the globes causes the influence of shortwave radiation to be overestimated, and thus decreased accuracy of $\mathrm{T}_{\mathrm{mrt}}$. 

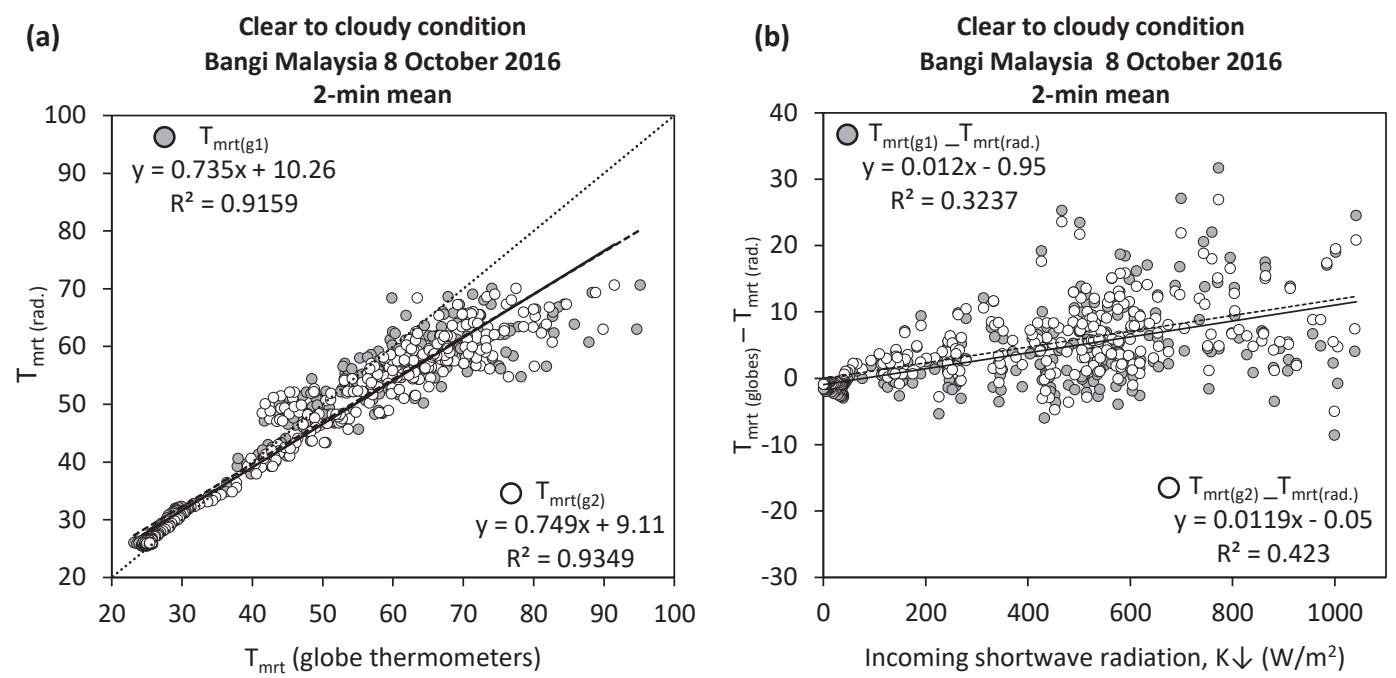

Fig. 4 (a-b); (a) $\mathrm{T}_{\text {mrt }}$ determined by integral radiation measurements, $\mathrm{T}_{\mathrm{mrt}}$ (rad.) versus that estimated by $50 \mathrm{~mm}$ copper globe thermometer, $T_{\mathrm{mrt}(\mathrm{g} 1)}$ and $150 \mathrm{~mm}$ copper globe thermometer, $\mathrm{T}_{\mathrm{mrt}}(\mathrm{g} 2)$; (b) $\mathrm{T}_{\mathrm{mrt}}(\mathrm{g} 1)$ and $\mathrm{T}_{\mathrm{mrt}}(\mathrm{g} 2)$ differences to $\mathrm{T}_{\mathrm{mrt}}$ (rad.) versus incoming short-wave radiation, $\mathrm{K} \downarrow$.

In Fig. 5, $\mathrm{T}_{\mathrm{mrt}}(\mathrm{g} 1)$ and $\mathrm{T}_{\mathrm{mrt}(\mathrm{g} 2)}$ differences to $\mathrm{T}_{\mathrm{mrt}}$ (rad.) were plotted against wind speed. The results indicate that wind speed fluctuation had a slightly higher influence on the small globe, causing a higher scattering in the calculated $\mathrm{T}_{\text {mrt }}$ values (lower $\mathrm{R}^{2}$ ). 


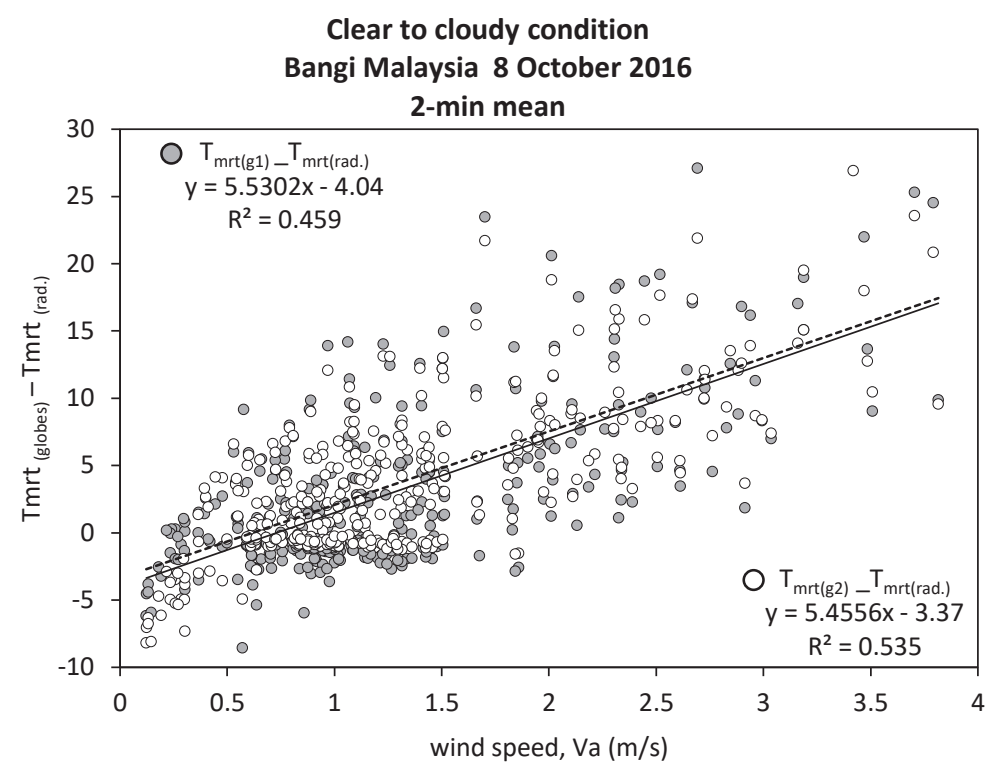

Fig 5: $\mathrm{T}_{\mathrm{mrt}(\mathrm{g} 1)}$ and $\mathrm{T}_{\mathrm{mrt}(\mathrm{g} 2)}$ differences to $\mathrm{T}_{\mathrm{mrt}}$ (rad.) versus wind speed

\section{CONCLUSION}

In this study globe thermometer method was used to estimate $\mathrm{T}_{\text {mrt }}$ using two blackpainted copper globes of $50 \mathrm{~mm}$ and $150 \mathrm{~mm}$ in diameters. Estimated $\mathrm{T}_{\mathrm{mrt}}$ results were compared with integral radiation measurements as a reference method. The study showed that, in tropical outdoor urban setting, the globe thermometer method overestimated $\mathrm{T}_{\mathrm{mrt}}$ during the middle of the day. In morning and late evening the difference between $T_{\text {mrt }}$ data from the two methods became relatively small. The globe temperatures of the large and small globes increased as the amount of radiation increased, resulting in a reduced accuracy of the estimated $\mathrm{T}_{\mathrm{mrt}}$.

The results also showed that the obtained $\mathrm{T}_{\text {mrt }}$ values from the large and small globes fluctuated greatly with time; their differences from the reference $T_{\text {mrt }}$ resulted in a large scatter in the function of radiation and wind speed. Furthermore, results showed that the small globe has a shorter delay to changes in outdoor conditions than the large globe. However, it gives slightly higher scatter in $\mathrm{T}_{\text {mrt }}$ values than the large globe, particularly during rapid changes in radiation and wind speed.

\section{REFERENCES}


[1] Matzarakis A, Rutz F, Mayer H. Modelling radiation fluxes in simple and complex environments: basics of the RayMan model. International Journal of Biometeorology. 2010;54:131-9.

[2] Gulyás Á, Unger J, Matzarakis A. Assessment of the microclimatic and human comfort conditions in a complex urban environment: modelling and measurements. Building and Environment. 2006;41:1713-22.

[3] Ali-Toudert F, Djenane M, Bensalem R, Mayer H. Outdoor thermal comfort in the old desert city of Beni-Isguen, Algeria. Climate Research. 2005;28:243-56.

[4] Höppe P. A new procedure to determine the mean radiant temperature outdoors. Wetter und Leben. 1992;44:147-51.

[5] Tan CL, Wong NH, Jusuf SK. Outdoor mean radiant temperature estimation in the tropical urban environment. Building and Environment. 2013;64:118-29.

[6] Johansson E, Thorsson S, Emmanuel R, Krüger E. Instruments and methods in outdoor thermal comfort studies-The need for standardization. Urban Climate. 2014;10:346-66.

[7] ISO I. 7726, Ergonomics of the Thermal Environment, Instruments for Measuring Physical Quantities. Geneva: International Standard Organization. 1998.

[8] Alfano FRdA, Dell'Isola M, Palella BI, Riccio G, Russi A. On the measurement of the mean radiant temperature and its influence on the indoor thermal environment assessment. Building and Environment. 2013;63:79-88.

[9] Thorsson S, Lindberg F, Eliasson I, Holmer B. Different methods for estimating the mean radiant temperature in an outdoor urban setting. International Journal of Climatology.

2007;27:1983-93.

[10] Kántor N, Unger J, Gulyás Á. Subjective estimations of thermal environment in recreational urban spaces-Part 2: international comparison. International Journal of Biometeorology. 2012;56:1089-101.

[11] Nikolopoulou M, Lykoudis S. Thermal comfort in outdoor urban spaces: analysis across different European countries. Building and Environment. 2006;41:1455-70.

[12] Wang S, 王上. Development of globe thermometers for measuring radiation and air speed. HKU Theses Online (HKUTO). 2015.

[13] Kántor N, Kovács A, Lin T-P. Looking for simple correction functions between the mean radiant temperature from the "standard black globe" and the "six-directional" techniques in Taiwan. Theoretical and Applied Climatology. 2015;121:99-111.

[14] Kuehn L, Stubbs R, Weaver R. Theory of the globe thermometer. Journal of applied physiology. 1970;29:750-7.

[15] Spagnolo J, De Dear R. A field study of thermal comfort in outdoor and semi-outdoor environments in subtropical Sydney Australia. Building and Environment. 2003;38:721-38.

[16] Nikolopoulou M, Baker N, Steemers K. Improvements to the globe thermometer for outdoor use. Architectural Science Review. 1999;42:27-34.

[17] Handbook A. Fundamentals. American Society of Heating, Refrigerating and Air Conditioning Engineers, Atlanta. 2001;111. 